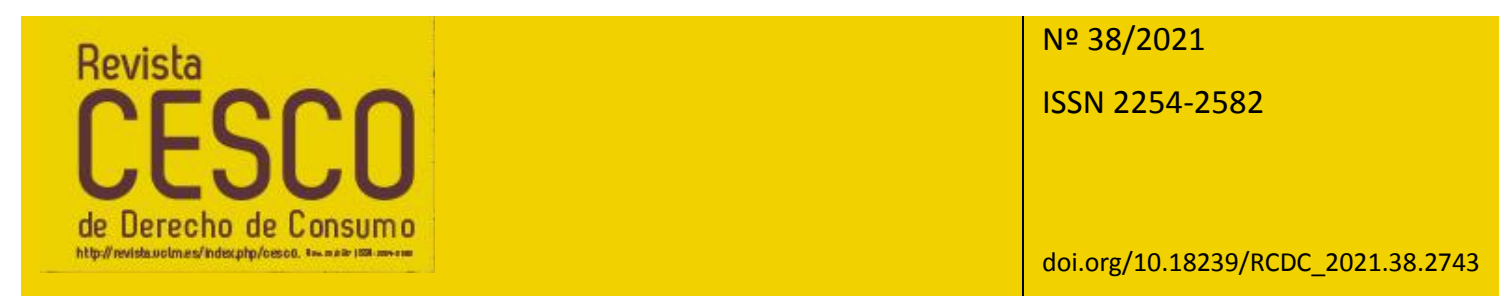

\title{
¿ABRIR EL GRIFO EQUIVALE A CELEBRAR UN CONTRATO? EL TRIBUNAL DE JUSTICIA DE LA UNIÓN EUROPEA SE PRONUNCIA SOBRE LOS SUMINISTROS NO CONSENTIDOS*
}

\author{
Alba García Hernández \\ Centro de Estudios de Consumo \\ Universidad de Castilla - La Mancha
}

\begin{abstract}
Resumen: El Tribunal de Justicia de la Unión Europea se ha pronunciado acerca de los suministros no consentidos, por medio de la resolución de cuestiones prejudiciales presentadas por el Tribunal Supremo de los Países Bajos. Si bien es cierto que delega cuestiones relevantes a los tribunales nacionales para que resuelvan de acuerdo con el ordenamiento interno, de tal resolución se deducen dos cuestiones relevantes en el ámbito de los suministros, que serán analizadas en el presente trabajo: 1) qué es un contrato no consentido y 2) cuándo y cómo se entiende prestado el consentimiento debido para la perfección de contrato.
\end{abstract}

Palabras clave: agua potable, contrato de suministros, consentimiento, perfección de contrato

Title: Does turning on the tap amount to entering into a contract? The European Court of Justice rules on non-consented supplies

\footnotetext{
* Trabajo realizado en el marco del Contrato con referencia 2020-COB-9996 financiado con cargo a la ayuda para la realización de proyectos de investigación científica y transferencia de tecnología, de la Junta de Comunidades de Castilla-La Mancha cofinanciadas por el Fondo Europeo de Desarrollo Regional (FEDER) para el Proyecto titulado "Protección de consumidores y riesgo de exclusión social en Castilla-La Mancha" (PCRECLM) con Ref.: SBPLY/19/180501/000333 dirigido por Ángel Carrasco Perera y Ana Isabel Mendoza Losana; en el marco del Proyecto de Investigación PGC2018-098683-B-I00, del Ministerio de Ciencia, Innovación y Universidades (MCIU) y la Agencia Estatal de Investigación (AEI) cofinanciado por el Fondo Europeo de Desarrollo Regional (FEDER) titulado "Protección de consumidores y riesgo de exclusión social", dirigido por Ángel Carrasco Perera y Encarna Cordero Lobato; a la Ayuda para la financiación de actividades de investigación dirigidas a grupos de la UCLM Ref.: 2020-GRIN-29156, denominado "Grupo de Investigación del Profesor Ángel Carrasco" (GIPAC) y en el marco del Proyecto Convenio de colaboración entre la UCLM y el Ilustre Colegio Notarial De Castilla-La Mancha (17 enero 2014) (OBSV) con referencia CONV140025, que dirige el Prof. Ángel Carrasco Perera.
} 


\begin{abstract}
The European Court of Justice has ruled on non-consensual supplies, by means of the resolution of preliminary questions submitted by the Supreme Court of the Netherlands. Although it delegates relevant issues to the national courts to resolve according to domestic law, two relevant questions related to supplies can be deduced, which will be analyzed in this paper: 1) what is a non-consented contract and 2) when and how is it understood that the consent required for the perfection of the contract has been given.
\end{abstract}

Keywords: potable water, supply contract, consent, contract perfection

SUMARIO: 1. Introducción. 2. Planteamiento del caso. 3. Marco jurídico europeo. 4. Marco jurídico nacional: el derecho neerlandés. 5. Cuestiones prejudiciales. 5.1. Primera cuestión prejudicial: ¿es necesaria la solicitud previa del servicio? 5.2. Segunda cuestión prejudicial: formalización del contrato de suministro. 6. Conclusiones. 7. Bibliografía.

\title{
1. Introducción
}

El Tribunal Supremo de los Países Bajos eleva cuestión prejudicial al Tribunal de Justicia de la Unión Europea (en adelante, TJUE o el Tribunal europeo) para que se pronuncie sobre la interpretación que ha de realizarse del término suministro consentido.

La materia objeto de debate radica en el siguiente tema: una empresa abastecedora de agua potable reclama el pago de los servicios prestados al destinatario de estos, quien alega la inexistencia de solicitud previa a la prestación de este servicio.

El Tribunal neerlandés se dirige al TJUE para aclarar dos cuestiones: 1) la primera de las dudas que plantea es si el suministro de agua puede entenderse como no consentido o aceptado por el consumidor cuando no concurre manifestación expresa al respecto y 2) si del comportamiento del usuario se presume una actitud proclive a la perfección de contrato entre las partes.

\section{Planteamiento del caso}

El asunto C-922/19 se residencia en una petición de decisión prejudicial planteada por el Tribunal Supremo de los Países Bajos, por medio de resolución dictada con fecha de 13 de diciembre de 2019 y recibida, posteriormente, por el TJUE el 17 de diciembre de 2019. El caso enfrenta a una organización empresarial distribuidora de agua potable y a un consumidor a quien se le reclama el pago de facturas del consumo de agua suministrado por la empresa.

Las cuestiones prejudiciales planteadas ante el TJUE tienen por asunto principal la aclaración interpretativa de los siguientes preceptos, incardinados en el ordenamiento europeo: 
10. Art. 9 de la Directiva 97/7/CE del Parlamento Europeo y del Consejo de 20 de mayo de 1997 relativa a la protección de los consumidores en materia de contratos a distancia (en adelante, la Directiva 97/7/CE), por el que se establecen instrucciones dirigidas a los Estados miembros ante la prestación de un suministro no deseado.

Los Estados miembros adoptarán las medidas necesarias para:

- prohibir los suministros de bienes o de servicios al consumidor sin encargo previo de éste, cuando dichos suministros incluyan una petición de pago;

- dispensar al consumidor de toda contraprestación en caso de suministro no solicitado, sin que la falta de respuesta pueda considerarse como consentimiento

$2^{\circ}$. Art. 27 de la Directiva 2011/83/UE del Parlamento Europeo y del Consejo de 25 de octubre de 2011 sobre los derechos de los consumidores, por la que se modifican la Directiva 93/13/CEE del Consejo y la Directiva 1999/44/CE del Parlamento Europeo y del Consejo y se derogan la Directiva 85/577/CEE del Consejo y la Directiva 97/7/CE del Parlamento Europeo y del Consejo (en adelante, la Directiva 2011/83/UE), por el que se determina, respecto a los suministros no deseados, que:

Se eximirá al consumidor de toda obligación de entregar contraprestación alguna en caso de suministro no solicitado de bienes, agua, gas, electricidad, calefacción mediante sistemas urbanos, de contenido digital o de prestación de servicios no solicitada, prohibido por el artículo 5, apartado 5, y el anexo I, punto 29, de la Directiva 2005/29/CE. En dicho caso, la falta de respuesta del consumidor a dicho suministro o prestación no solicitada no se considerará consentimiento.

30. Arts. 5.5. y 29 del Anexo I de la Directiva 2005/29/CE del Parlamento Europeo y del Consejo de 11 de mayo de 2005 relativa a las prácticas comerciales desleales de las empresas en sus relaciones con los consumidores en el mercado interior, que modifica la Directiva 84/450/CEE del Consejo, las Directivas 97/7/CE, 98/27/CE y 2002/65/CE del Parlamento Europeo y del Consejo y el Reglamento (CE) no 2006/2004 del Parlamento Europeo y del Consejo («Directiva sobre las prácticas comerciales desleales») (en adelante, la Directiva 2005/29/CE), por el que se prohíben las prácticas comerciales desleales, en el artículo 5, y se alude a las prácticas comerciales agresivas en el precitado art. 29:

1. Se prohibirán las prácticas comerciales desleales.

2. Una práctica comercial será desleal si: 
a. es contraria a los requisitos de la diligencia profesional,

b. y distorsiona o puede distorsionar de manera sustancial, con respecto al producto de que se trate, el comportamiento económico del consumidor medio al que afecta o al que se dirige la práctica, o del miembro medio del grupo, si se trata de una práctica comercial dirigida a un grupo concreto de consumidores.

3. Las prácticas comerciales que puedan distorsionar de manera sustancial, en un sentido que el comerciante pueda prever razonablemente, el comportamiento económico únicamente de un grupo claramente identificable de consumidores especialmente vulnerables a dichas prácticas o al producto al que se refieran, por padecer estos últimos una dolencia física o un trastorno mental o por su edad o su credulidad, deberán evaluarse desde la perspectiva del miembro medio de ese grupo. Ello se entenderá sin perjuicio de la práctica publicitaria habitual y legítima de efectuar afirmaciones exageradas o afirmaciones respecto de las cuales no se pretenda una interpretación literal.

4. En particular, serán desleales las prácticas comerciales que:

a. sean engañosas según lo establecido en los artículos 6 y 7,o

b. sean agresivas según lo establecido en los artículos 8 y 9. 5 . En el anexo I figura una lista de las prácticas comerciales que se considerarán desleales en cualquier circunstancia. La misma lista única se aplicará en todos los Estados miembros y sólo podrá modificarse mediante una revisión de la presente Directiva.

\section{Marco jurídico europeo}

Como primera aproximación a la delimitación conceptual del término suministro no solicitado, se ha de tener en cuenta que la Directiva $97 / 7$, en su considerando 16 , manifiesta que "la técnica de promoción consistente en enviar un producto o proporcionar un servicio a título oneroso al consumidor sin petición previa o acuerdo explícito por parte de este, siempre que no se trate de un suministro de sustitución, no puede admitirse".

En este punto, ¿qué se ha de entender por petición previa o acuerdo explícito? La respuesta a esta cuestión radica en la base más elemental del Derecho: se entiende por acuerdo explícito el encuentro o coincidencia de voluntades entre varias partes, en aras de lograr un efecto determinado y concreto. Además, el hecho de que se exija que este sea explícito, supone que el acuerdo se ha de producir de manera clara, de forma que no se deje cuestión alguna al arbitrio posterior de alguna de las 
partes, sino que las condiciones rectoras del pacto sean recogidas en su totalidad en dicho acuerdo. Por tanto, podría decirse que, por petición previa o acuerdo explícito, se entiende la existencia de un verdadero acto positivo de las partes por el que estas se obligan a algo, en este caso, a la prestación de un suministro previamente solicitado. De este modo, salvo que se tratara de un suministro de sustitución, queda prohibido al prestador proveer el suministro si el consumidor expresamente no lo ha requerido anteriormente.

El control y fiscalización de tales servicios queda conferido a los Estados miembros, quienes deberán articular e implementar las medidas y actuaciones necesarias para evitar tales prácticas, especialmente cuando la provisión del suministro incluya una petición de pago al consumidor. La delimitación de estas funciones deberá desarrollarse sin perjuicio de lo previsto en los ordenamientos nacionales.

Asimismo, se reconoce el "derecho" o, mejor dicho, el privilegio al usuario que haya sido destinatario de tales prácticas comerciales de quedar eximido de realizar contraprestación alguna por los servicios prestados, que no hubieran sido solicitados por él. Resulta especialmente relevante la aclaración que precisa el art. 27 de la Directiva 2011/83, por la que expresa que "la falta de respuesta del consumidor a dicho suministro o prestación no solicitada no se considerará consentimiento", por tanto, el mutismo o silencio del usuario no podrá entenderse como respuesta análoga a un pronunciamiento efectivo de aceptación, sino que, para entender consentida la prestación del servicio es necesario una expresión o actitud proactiva de este por el que expresamente manifiesta la aceptación del servicio.

En estos términos, el ordenamiento jurídico europeo califica estas prácticas comerciales como desleales por resultar perjudiciales para "los intereses económicos de los consumidores $y$, por ende, indirectamente perjudiciales para los de los competidores legítimos"1. Además, puntualiza que todas aquellas técnicas que tengan por objeto "exigir el pago inmediato o aplazado, la devolución o la custodia de productos suministrados por el comerciante, pero que no hayan sido solicitados por el consumidor (suministro no solicitado), salvo cuando el producto en cuestión sea un producto de sustitución suministrado"2serán consideradas prácticas comerciales desleales bajo cualquier circunstancia.

Como garantía del principio de seguridad jurídica, las actividades o servicios constitutivos de prácticas comerciales desleales han sido tasadas por la legislación. Además, el marco europeo introduce una nueva y diferente clasificación a las prácticas comerciales desleales, aunque integradas en esta categoría: las prácticas comerciales agresivas, esto es, "toda práctica comercial que [...] merme o pueda mermar de forma importante, mediante el acoso, la coacción, incluido el uso de la fuerza, o la influencia indebida, la libertad de elección o conducta del consumidor

1 Considerando 6 de la Directiva 2005/29.

2 Punto 29 del Anexo I de la Directiva 2005/29. 
medio con respecto al producto y, por consiguiente, le haga o pueda hacerle tomar una decisión sobre una transacción que de otra forma no hubiera tomado"3.

Por tanto, del marco jurídico europeo se deducen las siguientes premisas:

$1^{\circ}$. Las técnicas comerciales consistentes en el envío de un producto o la provisión de un servicio a título oneroso quedan prohibidas cuando no hubieran sido demandadas por el cliente.

$2^{\circ}$. La prestación de suministros ha de ser siempre consentida por el destinatario y solicitada de manera previa por este. En consecuencia, la solicitud del usuario ha de ser expresa y clara, salvo que se trate de un suministro de sustitución.

Tras la exposición de estas dos primeras apreciaciones, resulta evidente la necesidad de consentimiento por parte del suministrado, pues, "constituye esta la conducta significativa, a la que se atribuye la creación de la específica regla negocial y de la que resulta la responsabilidad consiguiente". Es a partir del momento en el que tiene lugar la declaración de voluntad del consumidor cuando se aprecia la perfección de la relación contractual entre las partes; sin embargo, cabe plantearse aquí si es necesario que el consentimiento sea recogido en documento escrito o se presume la conformidad del usuario mediante el uso del bien o servicio prestado, cuestión que será analizada más adelante.

30. Estas prácticas comerciales son desleales por suponer un perjuicio grave en los intereses económicos de los consumidores y una merma y alteración considerable del marco económico interno de cada país. Tienen como característica definitoria la exigencia de pago inmediato o aplazado, a pesar de la falta de solicitud del usuario.

$4^{\circ}$. Los Estados miembros son los responsables del control de tales prácticas comerciales, de conformidad con lo establecido en los ordenamientos internos.

50. El consumidor destinatario las prestaciones quedará eximido del pago de los servicios que le hubieran sido provistos sin su consentimiento.

60. La falta de respuesta del consumidor no se entenderá como aceptación.

\section{Marco jurídico nacional: el derecho neerlandés}

En relación con la controversia que aquí se plantea, se han de tener en cuenta dos consideraciones: en un primer estadio, se trata de dilucidar cuál es el plan de actuación que enmarca el ordenamiento interno en lo referido a la recepción o provisión de un bien o servicio no demandado por el cliente y, de manera más concreta, avanzando hacia un segundo estadio, se ha de analizar cómo influyen las directrices generales sobre un campo más específico: el suministro de agua potable.

3 Art. 8 de la Directiva 2005/29. 
El Código Civil neerlandés prohíbe el envío a una persona física de un bien que no lo haya demandado y la exigencia posterior de pago, siempre que la persona destinataria no actúe en calidad de profesional o empresario. Es más, manifiesta que no surge obligación de pago alguna para el usuario cuando la prestación de servicios (agua, gas, calefacción, electricidad, productos financieros, etc.) no hubiera sido solicitada, incluso si se demostrara la concurrencia de una situación pasiva en el potencial cliente, esto es, cuando no se produjera una demostración activa de tal aceptación. Sin embargo, si, a pesar de las restricciones impuestas por el orden jurídico en este sentido, estas no fueran respetadas y el proveedor decidiera mantener el envío del bien, se reconoce el derecho del usuario a conservarlo a título gratuito.

De otra parte, de manera sucinta por la complejidad de la cuestión que aquí ocupa, de acuerdo con lo recogido en la Ley de agua de los Países Bajos, se puede afirmar lo siguiente:

- La ejecución del abastecimiento público de agua potable corresponde al propietario de la empresa de agua potable facultada para la prestación de tal servicio.

En este aspecto, surge aquí cierta controversia que dotaría de especiales singularidades al caso y que podría condicionar su resolución, respecto al suministro de otros bienes liberalizados. Anteriormente se mencionaba que, una de las razones para prohibir el suministro no solicitado $y$, correlativamente, impedir exigir el pago es la protección de terceros competidores que, de admitirse esta práctica, podrían ver mermadas sus posibilidades de acceder al mercado; con todo, nos encontramos ante un servicio claramente monopolizado, pues es la empresa concesionaria quien ofrece exclusivamente el suministro sin la competencia de otros agentes, por lo que la protección a terceros que en este punto se brinda se convierte en un auténtico sinsentido.

- El propietario de la empresa de agua estará obligado a ofertar servicios a todo aquel que lo solicite, con una triple finalidad:

- Abastecer de agua potable a los ciudadanos por medio de la red de conducción de cuya gestión se encuentra al cargo.

- Aumentar la conectividad y ampliar el alcance de la red de conducción de agua.

- Mejorar y optimizar el abastecimiento a los pequeños consumidores, a quienes el propietario de la distribuidora de agua no podrá interrumpir el abastecimiento a causa del impago del servicio prestado, salvo cumplimiento del proceso previo especificado en la normativa correspondiente y tras haber requerido el pago en las condiciones previstas en la misma.

Como aclaración a la prohibición que se impone sobre la posibilidad de interrumpir el abastecimiento, cabe decir que tal circunstancia deriva de la naturaleza especial del 
suministro de agua, ya que se trata de un servicio calificado como esencial. Así pues, de acuerdo con esta especial consideración, la empresa suministradora se encuentra obligada a ofrecerlo necesariamente y solo podrá negarlo o interrumpirlo cuando concurran las causas legales así previstas. De otra parte, pese a que el suministro de agua reviste la denominación de servicio esencial, se reconoce al abonado la facultad de renunciar al mismo cuando así lo deseara; de manera que, el proveedor de un servicio esencial no puede impedir que este sea prestado a quien lo solicite con motivo de su contribución al sostenimiento de los intereses generales; sin embargo, el beneficiario del servicio sí puede renunciar a él.

Por tanto:

10. Naturalmente, el derecho neerlandés reproduce las cuestiones contempladas por las normas europeas. Se prohíbe el envío no solicitado de bienes o la prestación no demandada de servicios por el usuario.

$2^{\circ}$. Ante el incumplimiento del mandato anterior, el consumidor no estará obligado a la contraprestación del servicio, incluso, podrá mantener el bien recibido a título gratuito.

30. Respecto al suministro de agua potable, el responsable del abastecimiento es el propietario de la empresa abastecedora. No existen competidores en la prestación de este servicio.

40. No podrá ser privado el pequeño consumidor de los servicios de agua potable por impago, salvo excepciones.

\section{Cuestiones prejudiciales}

El litigio principal sobre el que se residencia el proceso se refiere a los siguientes hechos:

- Stichting Waternet es la empresa distribuidora de agua en Ámsterdam, donde se encuentra la residencia, desde 2012, del consumidor al que se reclama el pago de los servicios prestados.

- El usuario no informó a la empresa de su traslado a su nuevo domicilio, situación que ya se había producido previamente con el anterior propietario, aunque, en este caso, lo que no se comunicó fue el cambio de residencia y la baja del servicio, de manera que continuó pagando las facturas por el suministro de agua hasta el año 2014.

- En ese año, la empresa envío carta de bienvenida al nuevo usuario y, a finales de año, le remitió las facturas relativas a la distribución de agua desde comienzo de año. Tales facturas y otras posteriores no fueron satisfechas por el cliente.

- Stichting Waternet presentó demanda en la que pretendía el reconocimiento de la deuda y el pago de esta, así como, de forma subsidiaria, que se le facultara para poder cortar el suministro.

- El órgano jurisdiccional desestimó la pretensión de pago de la demandante por entender que el servicio constituía un suministro no solicitado. 
- La empresa distribuidora recurrió en apelación la sentencia, recurso que fue, de nuevo, desestimado. La cuestión fue trasladada al Tribunal Supremo de los Países Bajos.

- El Alto Tribunal neerlandés plantea ante el TJUE cuestión prejudicial por la que plantea si la técnica comercial empleada es inherente a la consideración de un suministro como no solicitado expresamente por el destinatario de este.

El órgano neerlandés, para favorecer el esclarecimiento del asunto planteado, realiza las siguientes apreciaciones:

- Que el mercado de la distribución del agua no se ajusta a las características propias de un mercado competitivo, ya que el abastecimiento de agua es, en aquel país, una función esencial de carácter público.

- Que la empresa responsable del servicio deberá realizar una oferta a quien así lo solicite.

- Que no se podrá interrumpir el servicio en base a un incumplimiento en el pago.

Que los ciudadanos de los Países Bajos son conscientes de que sus viviendas se encuentran conectadas a la red de abastecimiento de agua potable, no siendo este servicio gratuito.

\subsection{Primera cuestión prejudicial: ¿es necesaria la solicitud previa del servicio?}

La primera cuestión remitida trata de dilucidar si concurre suministro de agua potable no solicitado cuando la empresa suministradora cumple las siguientes características en virtud de normal legal:

- La empresa abastecedora se encuentra "dentro de la zona de distribución que le ha sido asignada, facultada con carácter exclusivo y obligada a suministrar agua potable por medio de tuberías, y obligada a presentar a quien se lo solicite una oferta de conexión a la red pública de abastecimiento de agua potable y a presentar una oferta de suministro de agua potable".

- "La empresa de abastecimiento de agua potable mantiene la conexión de la vivienda del consumidor a la red pública de abastecimiento de agua potable tal como existía antes de que el consumidor ocupase la vivienda, por lo que [...] podrá obtener agua si así lo desea, incluso después de que el consumidor haya comunicado que no desea celebrar ningún contrato para el suministro de agua potable".

El asunto principal sobre el que gira la cuestión que aquí se debate es si el concepto de suministro no solicitado, reconocido en la Directiva 2005/29, abraza aquella práctica comercial correspondiente a la situación en la que se trata de mantener la conexión a la red pública de distribución de agua potable sin previa solicitud, cuando se traslada el usuario a un nuevo domicilio, que ya contaba con tal servicio. 
En este aspecto, la competencia para dilucidar si las técnicas empleadas por la distribuidora Stichting Waternet se circunscriben al marco de las actuaciones que persiguen la protección de los intereses económicos individuales de los ciudadanos y aquellos relacionados con la competencia nacional le es atribuida al Tribunal neerlandés, quien, por consiguiente, habrá de considerar si tal prestación se incluye dentro de las tasadas como suministro no solicitado en la precitada directiva.

No obstante, en términos generales, el TJUE afirma que "constituye, pues, un «suministro no solicitado» [...] el comportamiento consistente en que el comerciante exija al consumidor el pago de un servicio suministrado al consumidor sin que este último lo haya solicitado". Expresa el Tribunal europeo que "la solicitud de un servicio debe ser una elección libre del consumidor. Ello requiere, en particular, que la información dada por el comerciante al consumidor sea clara y adecuada". En la información que se proporcione al consumidor debe incluirse aquella atinente al precio del producto o del servicio provisto, ya que adquiere un elemento determinante en la toma de decisiones del consumidor a la hora de decantarse por la aceptación de un servicio o bien determinado. A pesar de la importancia que se reconoce al precio, en este supuesto resulta irrelevante, ya que el servicio prestado no se desarrolla en competencia, sino que responde a una naturaleza monopolizada. Así pues, tomando en consideración este matiz, el papel del consumidor se limita aquí a las siguientes opciones: 1 ) cuando se trate de un "primer suministro", el papel del usuario se limitará a la contratación y 2) si el suministro ya existiera, le corresponde la subrogación en la posición del beneficiario anterior para el mantenimiento del servicio prestado o la baja de este.

Así pues, atendiendo a las particularidades del caso que aquí se presenta, la empresa abastecedora está obligada a prestar el servicio, el cual no puede quedar interrumpido ante el impago del usuario, sin que haya tenido lugar requerimiento de pago previo. De tal forma que, para que se generen costes que deban ser sufragados posteriormente por el beneficiario del servicio es necesario lo que el TJUE Ilama "acción voluntaria por parte del consumidor mediante el consumo de agua".

En atención a las precisiones que enuncia el TJUE, la expresión -suministro no solicitado- contemplada en el punto 29 del Anexo I de la Directiva 2005/29 responde a la siguiente interpretación:

"sin perjuicio de las comprobaciones que debe realizar el tribunal remitente, no abarca la práctica comercial de una empresa de distribución de agua potable consistente en mantener la conexión a la red pública de distribución de agua cuando se instala un consumidor en una vivienda que había estado previamente ocupada si dicho consumidor no puede elegir el proveedor de tal servicio, este proveedor factura, en función del consumo de agua, tarifas que cubren los costes y son transparentes y no discriminatorios, y dicho consumidor sabe que la citada 
vivienda está conectada a la red pública de distribución de agua y que el abastecimiento de agua es de pago".

Luego, el Tribunal Europeo valora el supuesto del que conoce en este momento como ajeno al alcance de las circunstancias propias de un suministro no consentido y ello por:

- La finalidad de las técnicas comerciales empleadas responde a la necesidad de mantener la conexión a la red pública de distribución de agua.

- El suministro ya estaba siendo prestado en el domicilio con anterioridad a la ocupación de este por su nuevo residente.

- Con todo, la razón más importante en este sentido se remite a un concepto extrajurídico y es el conocimiento medio del consumidor. Presume el Tribunal Europeo la capacidad idónea de entendimiento del cliente, a quien supone informado y consciente de las particularidades más básicas del servicio, por ejemplo, la obligación de pago a causa del abastecimiento de agua, cuando se refiere a que "dicho consumidor sabe $[\ldots]$ ".

\subsection{Segunda cuestión prejudicial: formalización del contrato de suministro}

La segunda cuestión planteada tiene un carácter más formal y es que se trata de demostrar si se produce efectivamente la perfección de un contrato de suministro de agua cuando concurren los siguientes requisitos:

- "El consumidor [...] sabe que el suministro de agua potable genera costes.

- El consumidor [...] consume sistemáticamente agua potable [...].

- El consumidor, aun después de haber recibido de la empresa de abastecimiento de agua potable una carta de bienvenida, facturas y requerimientos de pago, continúa consumiendo agua.

- El consumidor, una vez que se ha concedido una autorización judicial para proceder al cierre de la toma de agua potable de la vivienda, comunica que sí desea un contrato con la empresa de suministro de agua potable".

En palabras del TJUE, para abordar el asunto que aquí se trata, primero se ha de averiguar si la relación entre el prestador del servicio y el consumidor se aparta de las normas del derecho público, debido a la consideración de servicio de interés general de tal prestación. Así pues, apunta el Tribunal europeo que, en caso de ajustarse este nexo a los caracteres propios de una relación pública, la cuestión prejudicial resultaría improcedente. En este contexto, conviene puntualizar que, a pesar de la función pública que desempeña este servicio, la relación jurídica entre los contratantes se sigue sometiendo al Derecho privado, aunque sujeto al cumplimiento de ciertas particularidades como la prohibición de su interrupción, salvo causas excepcionales; prestación obligatoria del suministro, etc. Con todo, el TJUE manifiesta que tal vinculación es una cuestión de fondo que habrá de ser aclarada por el órgano jurisdiccional neerlandés. 
De otra parte, destaca el TJUE que la Directiva 97/7 tiene por objeto la protección integral de aquellos consumidores que hubieran celebrado contratos a distancia; sin embargo, esta norma no prevé cuestión alguna sobre la formación de los mencionados contratos. No obstante, como se ha venido mencionando a lo largo del presente trabajo, se deberá interpretar la normativa europea sin perjuicio del ámbito jurídico interno de cada Estado miembro; de manera que habrá que estar a lo dispuesto por los preceptos genéricos de la norma común, así como a las reglas internas de cada país.

Así pues, en la medida en que la formalización de los contratos de suministro no es un asunto cubierto por el marco común, deberá acudirse al Derecho contractual neerlandés para suplir tal laguna normativa ante la falta de armonización jurídica a este respecto.

Concluye, en consecuencia, el Tribunal Europeo que corresponde al Tribunal Supremo de los Países Bajos averiguar si "puede considerarse celebrado un contrato entre una empresa de distribución de agua y un consumidor sin el consentimiento expreso de este" a la vista del ordenamiento nacional.

Por tanto, cabe cuestionarse aquí la siguiente pregunta ¿es necesario que sea recogido en documento escrito o se presume la conformidad del usuario mediante el uso del bien o servicio prestado? A esta pregunta se podría responder con la siguiente expresión "si se sabe lo que se hace y si también se ha querido lo hecho [...] no habrá problemas"4; por tanto, el uso de un servicio podrá entenderse como manifestación de la aceptación de la parte beneficiaria de este siempre que tal disfrute sea consciente y sus consecuencias - por ejemplo, la obligación de pagosean conocidas.

Es más, a este respecto DE CASTRO presenta el siguiente ejemplo, el cual se ajusta a las características del caso que aquí se trata y puede resultar bastante esclarecedor: "un viajero toma un tranvía y paga su billete. Se observa: entonces, ¿dónde están las declaraciones de voluntad del viajero y de la compañía de tranvías? Ni el uno ni la otra han dicho nada. No hubo oferta ni aceptación, no existió consentimiento sobre condiciones. derechos adquiridos y obligaciones asumidas por los contratantes. De lo que se concluye que hay unos hechos y de ellos resulta una relación obligatoria" ${ }^{\prime}$. En este supuesto, las partes contratantes ni siquiera se conocen o han mantenido un contacto más o menos directo, pese a todo, de su comportamiento se deduce una conducta tan concluyente como si de una "stipulatio" se tratara. Por consiguiente, respondiendo a la cuestión que se planteaba, no es estrictamente necesario que se formalice un documento por escrito en el que se recoja el consentimiento del usuario del servicio, sino que basta la mera "conducta concluyente" del uso ${ }^{6}$, esto es, el consentimiento sobre

${ }^{4}$ DE CASTRO Y BRAVO, F., El negocio jurídico. Instituto Nacional de estudios jurídicos, 1971, op. cit, p. 58.

${ }^{5}$ DE CASTRO Y BRAVO, F., El negocio jurídico... op. cit, p. 43.

${ }^{6}$ DE CASTRO Y BRAVO, F., El negocio jurídico... op. cit, p. 44. 
las prestaciones es elemento suficiente para el perfeccionamiento del contrato ${ }^{7}$. De esta forma, el hecho de abrir el grifo y consumir el agua es una actuación más que constitutiva de la aceptación del usuario del servicio prestado.

Asimismo, aceptar que no hay contrato en este supuesto, supondría un enriquecimiento ilícito o sin causa del usuario, pues el usuario consume agua sin efectuar pago alguno, a pesar de conocer que el servicio no es prestado de manera gratuita. La figura del enriquecimiento sin causa ha sido definida por el Tribunal Supremo como aquella ventaja patrimonial que obtiene una de las partes de la relación negocial en aras del empobrecimiento de la otra, sin que exista justificación alguna que pudiera motivar tal "desplazamiento patrimonial", que no tiene por qué derivar de mala fe o negligencia ${ }^{8}$. El Alto Tribunal también ha determinado los requisitos que han de darse para que se aprecie enriquecimiento ilícito:

- Obtención de un beneficio. La ventaja no solo se debe a la obtención de un aumento del patrimonio, sino que debe existir, igualmente, un empobrecimiento en la otra parte, que no tiene por qué ser siempre un deterioro económico, sino que también puede deberse a una pérdida de expectativas o al cese de una actividad.

- Conexión entre el enriquecimiento y el empobrecimiento respectivo de las partes. Debe concurrir nexo causal entre ambas circunstancias

- Falta de causa que justifique el enriquecimiento de parte.

\section{Conclusiones}

EI TJUE, siguiendo la doctrina legislativa, limita la obligación de hacer frente a una contraprestación que, generalmente, se corresponde con el pago de un precio cuando el bien o servicio recibido no ha sido solicitado de manera expresa por el consumidor beneficiario. Hace hincapié en el hecho de que tal aceptación ha de tener origen en una manifestación concreta y no puede considerarse como tal el mutismo del usuario. Asimismo, valora estas prácticas comerciales como desleales por suponer una grave merma en los intereses individuales y colectivos y, con motivo de la gravedad que entraña el asunto, exime a los clientes al pago de una contraprestación, de tal modo que los podrán adquirir o disfrutar a título gratuito.

De manera particular, en relación con la prestación de servicios de suministro de agua potable, el TJUE concluye que:

10. Con carácter general, la valoración de si hay contrato o no, corresponde a los tribunales nacionales que aplicarán, a estos efectos, la normativa nacional.

$2^{\circ}$. El tribunal nacional valorará también, según el Derecho nacional, si es contrato de Derecho privado o relación sujeta al Derecho público.

\footnotetext{
7 Art. 1262 del Código Civil.

${ }^{8}$ En este contexto, véase la STS de 23 de octubre de 2003.
} 
30. No obstante, dadas las peculiaridades del suministro de agua, no se puede decir que sea un suministro no consentido, porque queda acreditado que los usuarios conocen que el servicio no es gratuito.

A pesar del fallo, conviene resaltar algunos aspectos sobre los que el Tribunal europeo no se ha pronunciado, pues se ha limitado a determinar que el objeto del contrato que sustenta la cuestión principal del litigio no se incardina en ámbito de los suministros no consentidos, remitiendo otras cuestiones relevantes, como la perfección del contrato o la naturaleza de la relación contractual surgida, al tribunal neerlandés. En esta línea, se ha de tener en cuenta que:

10. Podría decirse que la diferenciación entre los suministros consentidos y aquellos que no lo son radica en un concepto extrajurídico de extrema importancia en la doctrina actual: el conocimiento medio del consumidor. En base a este término, los órganos jurisdiccionales consideran que existen cuestiones entendidas $y$, sobre todo, asumidas por todos los ciudadanos en condiciones normales, como, por ejemplo, que el disfrute del servicio de abastecimiento de agua no es gratuito, sino que supone un coste que ha de ser satisfecho por su beneficiario.

$2^{\circ}$. De otra parte, el consentimiento se demuestra como un elemento esencial en el ámbito de la contratación, aunque despierta múltiples conflictos. Una de las cuestiones a resolver es si la declaración de voluntad de las partes en la celebración de un contrato ha de ser expresa y recogida por escrito o, por el contrario, el mero uso de los bienes o servicios provistos es más que suficiente para presumir el consentimiento. A este respecto, la doctrina clásica lo tiene claro: el uso de los servicios prestados constituye manifestación efectiva para sobreentender el consentimiento del usuario. Así pues, se habla de actos concluyentes, es decir, "comportamiento activos o positivos" que presuman la anuencia del consumidor. De igual manera que cuando se compra un billete de transporte o se introduce una moneda en una máquina expendedora no se expresa por escrito el consentimiento en la provisión de la prestación, pero se entiende celebrado un contrato -aunque el consumidor no caiga en la cuenta de ello-, el hecho de abrir el grifo tiene las mismas implicaciones; es un acto concluyente que perfecciona la formación de un contrato y la producción de unas obligaciones que se han de satisfacer al prestador. Así pues, el consumidor, con la finalidad de liberarse del pago no puede alegar la falta de consentimiento expreso, pues con sus actos confirma lo que no ha hecho con sus palabras.

30. Otra de las cuestiones que no esclarece el TJUE, aunque de menor entidad, es la naturaleza del contrato de suministro de agua potable. A pesar de su función pública, derivada de la satisfacción de un interés general, la relación contractual se somete al Derecho privado, aunque, como ya se ha mencionado, no es un contrato privado como cualquier otro, sino que reviste ciertas especialidades: la prestación es de carácter obligatorio, de manera que la empresa abastecedora no puede decidir con quién contrata y con quién no; 
el servicio no puede ser interrumpido, siquiera ante el incumplimiento del beneficiario, etc.

\section{Bibliografía}

DE CASTRO Y BRAVO, F., El negocio jurídico. Instituto Nacional de estudios jurídicos, 1971. 